\title{
Article \\ Effect of Early Basal Leaf Removal on Phenolic and Volatile Composition and Sensory Properties of Aglianico Red Wines
}

\author{
Debora Iorio $^{1}$, Giuseppe Gambacorta ${ }^{1, *(\mathbb{D})}$, Luigi Tarricone ${ }^{2} \mathbb{D}$, Mar Vilanova ${ }^{3, *(D)}$ and Vito Michele Paradiso ${ }^{4}(\mathbb{D}$ \\ 1 Department of Soil, Plant and Food Sciences, University of Bari Aldo Moro, Via Amendola, 165/A, \\ 70126 Bari, Italy; d.iorio1@studenti.uniba.it \\ 2 CREA, Council for Agricultural Research and Economics, Research Center for Viticulture and Enology, \\ Via Casamassima 148, 70010 Bari, Italy; luigi.tarricone@crea.gov.it \\ 3 Instituto de Ciencias de la Vid y del Vino (ICVV), Consejo Superior de Investigaciones Científicas, \\ CSIC-Universidad de La Rioja-Gobierno de La Rioja, Carretera de Burgos Km 6, 26080 Logroño, Spain \\ 4 Department of Biological and Environmental Sciences and Technologies, Laboratory of Agri-Food \\ Microbiology and Food Technologies, University of Salento, S.P. 6, Lecce-Monteroni, 73100 Lecce, Italy; \\ vito.paradiso@unisalento.it \\ * Correspondence: giuseppe.gambacorta@uniba.it (G.G.); mar.vilanova@csic.es (M.V.)
}

Citation: Iorio, D.; Gambacorta, G.; Tarricone, L.; Vilanova, M.; Paradiso, V.M. Effect of Early Basal Leaf Removal on Phenolic and Volatile Composition and Sensory Properties of Aglianico Red Wines. Plants 2022, 11, 591. https://doi.org/10.3390/ plants11050591

Academic Editor: Igor Jerković

Received: 23 January 2022

Accepted: 20 February 2022

Published: 22 February 2022

Publisher's Note: MDPI stays neutral with regard to jurisdictional claims in published maps and institutional affiliations.

Copyright: (C) 2022 by the authors. Licensee MDPI, Basel, Switzerland. This article is an open access article distributed under the terms and conditions of the Creative Commons Attribution (CC BY) license (https:// creativecommons.org/licenses/by/ $4.0 /)$.

\begin{abstract}
The aim of this work was to study the influence of early basal leaf removal on Aglianico wines produced in the Apulia region (Italy). Three treatments were carried out, where $100 \%$ of fruit-zone leaves on the north (DN), south (DS) and on both sides of the canopy (DNS) were removed. A control (CT), where all basal leaves were retained, was also performed. Instrumental (HPLCDAD-MS and GC-MS) and sensory analysis (QDA) were used to evaluate the treatment effect on the phenolic and volatile compositions and on the sensory descriptors of wines. DNS reached the highest amounts of phenolic compounds, showing a change in the phenolic pattern from flavonols and anthocyanins. Moreover, leaf removal influenced the levels of $37.8 \%$ of volatile compounds, quantified by increasing the concentration when early leaf removal was applied on the north side of the canopy (DN), with respect to the south (DS) and both sides (DNS). In the sensory analysis, Aglianico wines were defined by 16 sensory attributes with $\mathrm{GM}>30 \%$, where the highest values were reached for defoliation treatments vs. control. In conclusion, early leaf removal treatments allowed us to modulate the phenolic and volatile concentrations of Aglianico wines.
\end{abstract}

Keywords: early defoliation; phenolic profile; volatile profile; sensory analysis

\section{Introduction}

In the last decade, new viticulture techniques have been developed around the world for cost-effective canopy management, with the aim of improving grape and wine quality. Early basal leaf removal is an innovative viticulture practice aimed, on the one hand, at modulating the microclimate around the bunch and therefore reducing the incidence of bunch rot; on the other hand, it is aimed at enhancing the quality of grape and wine [1-4]. In previous studies, early leaf removal induced smaller and looser clusters that were less susceptible to Botrytis rot [2,4,5]. Moreover, this practice determines specific transcriptional modifications, involving the ripening program and the flavonoid metabolism [6]. Various effects of early leaf removal were reported, regarding concentrations of soluble solids, phenols and anthocyanins in grapes [1,2] and wines [5] from early defoliated vines. The expected positive impact of early leaf removal on grape and wine composition is based upon its effects on leaf/fruit ratio, canopy porosity, fruit (cluster and berry) exposure [4] and skin/berry ratio [7]. Furthermore, early leaf removal could be applied by a defoliator machine for cost-effective yield control with improved grape [1] and wine composition [5] and aroma attributes [8].

The modulation of phenolic contents and profiles is a main aim of viticultural practices in light of their cascading effect on the quality of grapes and finally of wines [8,9]. Several 
attempts have been made to adopt suitable practices with this aim [10,11]. Such viticultural practices are being also considered as tools for the adaptation to climate changes, that are severely impacting the phenolic ripening and equilibrium in grapes [12-15]. Improvement of wine bouquet is also of great interest to viticulturists and winemakers due to their importance to wine quality. Generally, wine aroma can be categorized as varietal aromas (terpenes, norisoprenoids and methoxypyrazines), fermentation aromas (higher alcohols and their acetates, as well as fatty acids and their ethyl esters) and aging aromas (volatile phenols). Varietal aromas of wine mainly derive from grapes and are subjected to genotypic and environmental factors (light, temperature and water availability) [16]. Given this, basal leaf removal can be an effective practice for directly modifying wine varietals aromas. Fermentation aromas are formed via fatty acid metabolism or amino acid metabolism by yeast activity during fermentation [17]. Furthermore, several studies have demonstrated that fatty acids and amino acids are sensitive to environmental factors [18-20]. Fatty acids in berries have shown diverse behaviors in different training systems [18], and concentrations of amino acids in berries have been altered by sunlight exposure $[19,20]$. Thus, it is possible that fermentation aromas can be affected by basal leaf removal by altering their substrate levels. Many studies have recently been conducted to investigate the influence of basal leaf removal on volatile compounds in grape and wine, but discrepancies exist among these studies. The controversial results across these studies indicate that the grape cultivar or clone [21,22], the climate condition [23], grape maturity [24] and the timing and severity of defoliation $[23,25,26]$ might be responsible for the varied effects of basal leaf removal on the aromatic properties of grape and wine.

Instrumental and sensory analyses allow researchers to study the phenolic and aromatic composition of the wines. Volatile and non-volatile components of the wine can be identified and quantified by chromatographic techniques, and the sensory impact of volatiles depends on their perception thresholds [27]. On the other hand, sensory analysis allows detection and description of qualitative and quantitative sensory components of a product by a trained panel of judges [28]. Sensory descriptive analysis [29] is one of the most comprehensive and informative tools used in sensory analysis. This technique can provide complete sensory description of a product such as wine. Information from instrumental and sensory data, is very important to establish the composition of wine. The relationship between instrumental and sensory data has been extensively studied [16,26,27,30-32].

In this sense, the aim of this work was to study the influence of early leaf removal in the vineyard on Aglianico wines quality from Apulia region (Italy). Instrumental (HPLCDAD-MS and GC-MS) and sensory analyses (QDA) were performed to evaluate this effect on phenolic and volatile composition and sensory descriptors of wines.

\section{Results}

\subsection{Oenological Parameters}

Table 1 shows the influence of the leaf removal treatments on the oenological parameters of Aglianico wines. ANOVA results, by treatment, are also shown. In general, early leaf removal led to wines of higher alcohol, and more total polyphenol index, whereas $\mathrm{pH}$ and titratable acidity and malic, tartaric, citric and acetic acids remained generally unaffected. Similar results were found in Tempranillo wines from Spain, where higher alcohol content, more intense colors and a larger total polyphenol index were shown when pre-bloom leaf removal was applied [26]. Our results also coincide with Diago et al. [8], who reported that mechanical leaf removal was more effective in reducing yield, cluster weight and number of berries than manual leaf pulling, by affecting the fruit microclimate. On the other hand, no increase in alcohol contents was observed after early leaf removal in Gamay, Nero d'Avola, Graciano and Carignan wines [5,24,33]. A recent meta-analysis [3] summarized the outputs of research about the effects of early leaf removal on grape production and quality parameters. The most relevant findings showed the lowering of bunch rot disease $(-61 \%)$ and the increase in berry total soluble solids $\left(+5.2 \%,{ }^{\circ}\right.$ Brix $)$, which was related to the increase in the leaf-to-fruit ratio. Regarding the response of other quality indices, 
rootstock and variety were the most relevant variables influencing the effects of early leaf removal, while the role of climate was less relevant.

Table 1. Enological parameters of Aglianico red wines from 2018 vintage, obtained by early basal leaf removal treatments.

\begin{tabular}{|c|c|c|c|c|c|c|c|c|c|}
\hline \multirow{2}{*}{ Parameters } & \multicolumn{2}{|c|}{$\mathrm{CT}$} & \multicolumn{2}{|c|}{ DN } & \multicolumn{2}{|c|}{ DS } & \multicolumn{2}{|c|}{ DNS } & \multirow{2}{*}{ Sig. } \\
\hline & Mean & SD & Mean & SD & Mean & SD & Mean & SD & \\
\hline Glucose + Fructose $(\mathrm{g} / \mathrm{L})$ & $0.12 \mathrm{a}$ & 0.02 & $0.31 \mathrm{c}$ & 0.01 & $0.24 \mathrm{~b}$ & 0.01 & $0.39 \mathrm{~d}$ & 0.02 & $* * *$ \\
\hline Ethanol (\%vol) & $13.17 \mathrm{a}$ & 0.03 & $13.52 \mathrm{c}$ & 0.03 & $13.32 \mathrm{~b}$ & 0.06 & $13.82 \mathrm{~d}$ & 0.03 & $* * *$ \\
\hline $\mathrm{PH}$ & 3.20 & 0.04 & 3.16 & 0.05 & 3.23 & 0.04 & 3.18 & 0.04 & ns \\
\hline Total acidity (g/L) & 5.89 & 0.20 & 6.12 & 0.20 & 5.81 & 0.22 & 6.10 & 0.19 & ns \\
\hline Tartaric acid (g/L) & 1.29 & 0.34 & 1.30 & 0.36 & 1.33 & 0.19 & 1.33 & 0.34 & ns \\
\hline Citric acid $(\mathrm{g} / \mathrm{L})$ & 0.26 & 0.01 & 0.28 & 0.02 & 0.26 & 0.01 & 0.27 & 0.00 & ns \\
\hline Malic acid (g/L) & 0.98 & 0.03 & 0.94 & 0.04 & 0.94 & 0.01 & 0.91 & 0.06 & ns \\
\hline Acetic acid (g/L) & 0.09 & 0.01 & 0.07 & 0.01 & 0.07 & 0.01 & 0.08 & 0.01 & ns \\
\hline IPT & $35.07 \mathrm{a}$ & 1.81 & $40.47 \mathrm{~b}$ & 0.76 & $36.00 \mathrm{a}$ & 1.31 & $40.20 \mathrm{~b}$ & 0.75 & $* *$ \\
\hline
\end{tabular}

Different letters indicate significant differences for Tukey's test at $p<0.05$. Signs: ${ }^{* *}$-significance at $p<0.01$; *** - significance at $p<0.001$; ns — not significant; CT-control; DN-defoliation on the north side of the canopy; DS - defoliation on the south side of the canopy; DNS - defoliation on both sides of the canopy.

\subsection{Analysis of Polyphenols}

Table 2 shows the influence of the defoliation treatments on the polyphenolic indices of the wines. All the indices related to polyphenols showed a significant increase in wines from early defoliated vines. Some variations of the effect of defoliation were observed based on the canopy side involved. When early leaf removal involved the north side, the highest levels of anthocyanins, total flavonoids and flavans reactive with vanillin (FRV) were reached. On the other hand, wines from vines defoliated on the south side presented the highest levels of proanthocyanidins. Leaf removal on both sides led to the highest levels of all the classes, except FRV, and therefore led to the maximum content of total polyphenols in wines. The FRV/P ratio, representing the degree of tannin condensation, was found to be lower in defoliated wines, especially on the south and north-south sides (0.43- 0.46 versus 0.56 for $\mathrm{CT}$ ), which implied a reduction in tannin reactivity and a predisposition to color and tannin stabilization of wines [34].

Table 2. Polyphenols and color indices of Aglianico red wines from 2018 vintage, obtained by early basal leaf removal treatments.

\begin{tabular}{|c|c|c|c|c|c|c|c|c|c|}
\hline \multirow{2}{*}{ Polyphenols Indices } & \multicolumn{2}{|c|}{ CT } & \multicolumn{2}{|c|}{ DN } & \multicolumn{2}{|c|}{ DS } & \multicolumn{2}{|c|}{ DNS } & \multirow{2}{*}{ Sig } \\
\hline & Mean & SD & Mean & SD & Mean & SD & Mean & SD & \\
\hline $\begin{array}{l}\text { Total anthocyanins } \\
(\mathrm{mg} / \mathrm{L})\end{array}$ & 294 c & 1 & 447 a & 4 & $337 \mathrm{~b}$ & 4 & 449 a & 4 & * \\
\hline $\begin{array}{l}\text { Total flavonoids } \\
(\mathrm{mg} / \mathrm{L})\end{array}$ & 1474 c & 4 & $1715 \mathrm{a}$ & 6 & $1562 \mathrm{~b}$ & 16 & 1735 a & 9 & * \\
\hline $\begin{array}{l}\text { Vanillin reactive } \\
\text { flavans }(\mathrm{mg} / \mathrm{L})\end{array}$ & $948 \mathrm{~b}$ & 44 & 1113 a & 24 & $1037 a b$ & 57 & $1014 a b$ & 34 & * \\
\hline $\begin{array}{l}\text { Proanthocyanidins } \\
(\mathrm{mg} / \mathrm{L})\end{array}$ & 1697 c & 125 & $2061 \mathrm{~b}$ & 94 & $2241 \mathrm{ab}$ & 100 & 2369 a & 121 & * \\
\hline $\begin{array}{l}\text { Total polyphenols } \\
\text { (mg/L) }\end{array}$ & 1709 c & 44 & $1969 \mathrm{~b}$ & 35 & $1895 \mathrm{~b}$ & 31 & 2159 a & 40 & * \\
\hline $\begin{array}{c}\text { Antioxidant activity } \\
(\mathrm{mmol} / \mathrm{L})\end{array}$ & $10.0 \mathrm{~b}$ & 0.5 & $12.2 \mathrm{a}$ & 0.4 & $12.3 \mathrm{a}$ & 0.4 & $13.3 \mathrm{a}$ & 0.3 & * \\
\hline Color intensity & $1.42 \mathrm{c}$ & 0.01 & $1.61 \mathrm{~b}$ & 0.01 & $1.63 \mathrm{~b}$ & 0.03 & $2.01 \mathrm{a}$ & 0.04 & * \\
\hline Hue & 0.53 & 0.01 & 0.52 & 0.01 & 0.53 & 0.01 & 0.52 & 0.01 & ns \\
\hline
\end{tabular}

Different letters indicate significant differences for Tukey's test at $p<0.05$. Signs: ${ }^{*}$-significance at $p<0.05$, ns-not significant; CT—control; DN—defoliation on the north side of the canopy; DS—defoliation on the south side of the canopy; DNS—-defoliation on both sides of the canopy. 
Individual polyphenols were identified by HPLC-MS (Table 3) and quantified by HPLC-DAD (Table 4). Figure 1 reports the biplot of the first two principal components obtained from the PCA of phenolic profiles. Leaf removal on both sides determined a general increase in wines of compounds from flavonoid biosynthesis compared with control wines, as a consequence of light exposure [35].

Table 3. Identification of polyphenols of Aglianico red wines from 2018 vintage, obtained by early basal leaf removal treatments.

\begin{tabular}{|c|c|c|c|c|c|}
\hline Compounds & $\begin{array}{l}\text { RT } \\
\text { min }\end{array}$ & $\underset{\mathrm{nm}}{\lambda \text { Monitored }}$ & $\begin{array}{l}\text { Molecular Ion } \\
\mathrm{m} / \mathrm{z}\end{array}$ & $\begin{array}{l}\text { Fragments } \\
\qquad m / z\end{array}$ & Standard \\
\hline \multicolumn{6}{|l|}{ Anthocyanins } \\
\hline Delphinidin-3-O-glucoside & 5.68 & 520 & 465 & 303 & No \\
\hline Petunidin-3-O-glucoside & 6.57 & 520 & 479 & 317 & No \\
\hline Malvidin-3-O-glucoside & 7.34 & 520 & 493 & 331 & Yes \\
\hline Malvidin-3-O-glu pyruvate & 7.75 & 520 & 561 & 399 & No \\
\hline Malvidin-3-O-glu acetaldehyde & 8.01 & 520 & 517 & 355 & No \\
\hline Malvidin (6-acetyl)-glucoside & 9.14 & 520 & 535 & 331 & No \\
\hline $\begin{array}{c}\text { Malvidin-3-trans(6-coumaroyl)-glucoside } \\
\text { Phenolic acids }\end{array}$ & & No \\
\hline Chlorogenic acid & 1.00 & 330 & 191 & 111,173 & Yes \\
\hline Gallic acid & 1.16 & 330 & 169 & 125 & Yes \\
\hline Caftaric acid & 2.11 & 330 & 311 & 149,179 & Yes \\
\hline Coutaric acid & 3.35 & 330 & 295 & 163,149 & Yes \\
\hline Fertaric acid & 4.81 & 330 & 325 & 193 & No \\
\hline \multicolumn{6}{|l|}{ Flavonols } \\
\hline Quercetin-3-glucuronide & 7.65 & 350 & 477 & 301 & Yes \\
\hline Miricetin & 8.59 & 350 & 317 & 151,179 & Yes \\
\hline Syringetin-3-glucoside & 8.93 & 350 & 507 & 345 & No \\
\hline Quercetin & 10.35 & 350 & 301 & 151,178 & Yes \\
\hline \multicolumn{6}{|l|}{ Flavanols } \\
\hline Procyanidins dimer-1 & 2.29 & 280 & 577 & 425,407 & No \\
\hline Catechin & 2.92 & 280 & 289 & 245,205 & Yes \\
\hline
\end{tabular}

RT-retention time.

Table 4. Concentration (mg/L) of wine polyphenols from Aglianico red wines obtained by early basal leaf removal treatments.

\begin{tabular}{|c|c|c|c|c|c|c|c|c|c|}
\hline \multirow{2}{*}{ Compounds } & \multirow{2}{*}{$\begin{array}{c}\text { CT } \\
\text { Mean }\end{array}$} & \multicolumn{3}{|c|}{ DN } & \multirow{2}{*}{$\begin{array}{c}\text { DS } \\
\text { Mean }\end{array}$} & \multicolumn{3}{|c|}{ DNS } & \multirow{2}{*}{ Sig. } \\
\hline & & SD & Mean & SD & & SD & Mean & SD & \\
\hline \multicolumn{10}{|c|}{ Anthocyanins } \\
\hline Delphinid-3-O-glucoside & $4.21 \mathrm{c}$ & 0.09 & $9.44 \mathrm{~b}$ & 0.90 & $3.51 \mathrm{c}$ & 2.13 & $17.08 \mathrm{a}$ & 2.63 & * \\
\hline Petunidin-3-O-glucoside & $7.76 \mathrm{c}$ & 0.86 & $17.59 \mathrm{~b}$ & 1.14 & $8.54 \mathrm{c}$ & 0.78 & $26.96 \mathrm{a}$ & 3.72 & * \\
\hline Malvidin-3-O-glucoside & $105.16 \mathrm{~d}$ & 2.15 & $207.65 \mathrm{~b}$ & 4.77 & $128.38 \mathrm{c}$ & 8.98 & $269.19 \mathrm{a}$ & 4.77 & * \\
\hline $\begin{array}{l}\text { Malvidin-3-O-glu } \\
\text { pyruvate }\end{array}$ & $56.72 \mathrm{a}$ & 3.22 & 27.17 c & 2.41 & $41.42 \mathrm{~b}$ & 3.17 & 59.51 a & 6.64 & * \\
\hline $\begin{array}{l}\text { Malvidin-3-O-glu } \\
\text { acetaldehyde }\end{array}$ & $39.79 \mathrm{~b}$ & 3.90 & $22.81 \mathrm{c}$ & 1.76 & $42.16 \mathrm{~b}$ & 0.87 & 57.18 a & 1.54 & * \\
\hline $\begin{array}{l}\text { Malvidin-(6-acetyl)-3 } \\
\text { glucoside }\end{array}$ & $9.05 \mathrm{c}$ & 5.32 & $15.14 b$ & 2.80 & $9.08 \mathrm{c}$ & 1.69 & 24.28 a & 2.08 & * \\
\hline $\begin{array}{l}\text { Malvidin-3-trans-(6- } \\
\text { coumaroyl)-glucoside }\end{array}$ & $8.25 \mathrm{c}$ & 1.30 & $16.19 \mathrm{~b}$ & 2.41 & $4.55 \mathrm{~d}$ & 1.21 & $23.01 \mathrm{a}$ & 2.15 & * \\
\hline Total (\%) & $\begin{array}{c}230.94 \mathrm{c} \\
(72)\end{array}$ & & $\begin{array}{c}315.99 \mathrm{~b} \\
(82)\end{array}$ & & $\begin{array}{l}237.64 \mathrm{c} \\
(74)\end{array}$ & & $\begin{array}{l}477.21 \mathrm{a} \\
(85)\end{array}$ & & * \\
\hline
\end{tabular}


Table 4. Cont.

\begin{tabular}{|c|c|c|c|c|c|c|c|c|c|}
\hline \multirow{2}{*}{ Compounds } & \multirow{2}{*}{$\frac{\mathrm{CT}}{\text { Mean }}$} & \multicolumn{3}{|c|}{ DN } & \multirow{2}{*}{$\begin{array}{c}\text { DS } \\
\text { Mean }\end{array}$} & \multicolumn{3}{|c|}{ DNS } & \multirow{2}{*}{ Sig. } \\
\hline & & SD & Mean & SD & & SD & Mean & SD & \\
\hline \multicolumn{10}{|c|}{ Phenolic acids } \\
\hline Chlorogenic acid & 1.59 & 0.82 & 0.84 & 0.66 & 1.24 & 0.44 & 0.76 & 0.06 & ns \\
\hline Gallic acid & 1.04 & 0.36 & 0.42 & 0.53 & 0.42 & 0.12 & 0.51 & 0.2 & ns \\
\hline Caftaric acid & 40.12 & 3.9 & 39.13 & 3.06 & 40.08 & 1.35 & 42.47 & 1.27 & ns \\
\hline Coutaric acid & 9.81 & 2.64 & 10.70 & 0.15 & 10.60 & 1.28 & 11.42 & 2.14 & ns \\
\hline Fertaric acid & 1.94 & 2.37 & 1.27 & 0.24 & 1.25 & 0.54 & 2.30 & 0.1 & ns \\
\hline Total (\%) & $54.5(17)$ & & $52.36(14)$ & & $53.59(17)$ & & $57.46(10)$ & & ns \\
\hline \multicolumn{10}{|c|}{ Flavonols } \\
\hline Quercetin-3-glucuronide & $5.25 \mathrm{~b}$ & 0.82 & $4.13 \mathrm{c}$ & 0.8 & $6.15 b$ & 0.72 & $8.91 \mathrm{a}$ & 0.27 & * \\
\hline Myricetin & $3.09 \mathrm{a}$ & 0.27 & $1.05 \mathrm{c}$ & 0.13 & $2.90 \mathrm{~b}$ & 0.14 & $3.56 \mathrm{a}$ & 0.34 & * \\
\hline Syringetin-3-glucoside & $7.58 \mathrm{a}$ & 1.41 & $1.84 \mathrm{~d}$ & 0.73 & $4.26 \mathrm{~b}$ & 0.63 & $3.29 c$ & 0.16 & * \\
\hline Quercetin & $2.33 \mathrm{~b}$ & 0.23 & $0.67 \mathrm{~d}$ & 0.09 & $1.97 \mathrm{c}$ & 0.1 & $2.90 \mathrm{a}$ & 0.14 & * \\
\hline Total (\%) & 18.25 a (6) & & 7.69 c (2) & & $15.28 \mathrm{~b}(5)$ & & 18.66 a (3) & & $*$ \\
\hline \multicolumn{10}{|c|}{ Flavanols } \\
\hline Procyanidin dimer1 & 5.99 & 1.11 & 4.09 & 1.06 & 3.73 & 0.55 & 4.85 & 0.98 & ns \\
\hline Catechin & 8.79 a & 1.75 & $4.45 \mathrm{~b}$ & 1.71 & $8.95 \mathrm{a}$ & 1.6 & $8.33 \mathrm{a}$ & 2.09 & $*$ \\
\hline Total (\%) & 14.78 a (5) & & $8.54 \mathrm{~b}(2)$ & & 12.68 a (4) & & 13.18 a (2) & & * \\
\hline \multicolumn{10}{|c|}{ Total Polyphenols } \\
\hline & $318.47 \mathrm{c}$ & & $384.58 \mathrm{~b}$ & & $319.19 \mathrm{c}$ & & $566.51 \mathrm{a}$ & & $*$ \\
\hline
\end{tabular}

Different letters indicate significant differences for Tukey's test at $p<0.05$. Signs: ${ }^{*}$ - significance at $p<0.05$; ns—not significant; CT—control; DN—defoliation on the north side of the canopy; DS—defoliation on the south side of the canopy; DNS - defoliation on both sides of the canopy.

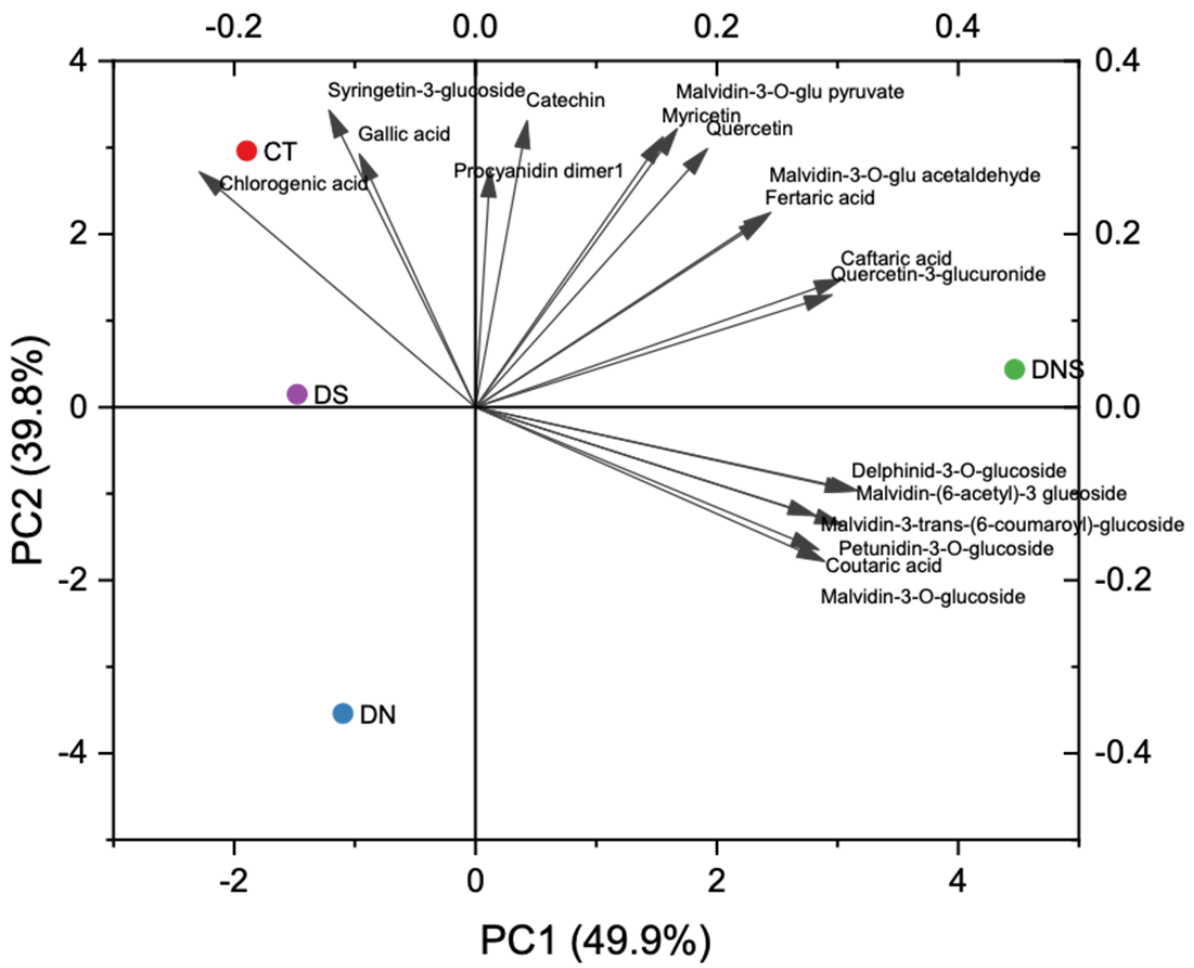

Figure 1. Principal components analysis of the phenolic profiles of Aglianico red wines obtained by early basal leaf removal treatments. CT-control; DN-defoliation on the north side of the canopy; DS—-defoliation on the south side of the canopy; DNS - defoliation on both sides of the canopy. 
Selective defoliation on either side impacted on wine phenolic profile as a consequence of a possible metabolic shift of phenolic compounds biosynthesis, from flavonol biosynthesis to anthocyanin biosynthesis, especially when defoliation on the north side was adopted. This could be attributed to the increase in anthocyanin biosynthesis with a competitive effect towards flavonols pathway [36]. DS wines only presented slight changes compared with control, while DN wines showed more evident differences. Compared with the effects of partial leaf removal on anthocyanin profiles of grape berries [37], some discrepancies were observed. In fact, leaf removal on the south side of the canopy determined higher levels of free monoglycosides in Aglianico berries [37] with respect to leaf removal on the north side. In wines, the opposite trend was observed.

On the other hand, higher levels of pyranoanthocyanins (vitisin A and vitisin B) were observed in DS wines compared with DN wines. Therefore, leaf removal treatments also affected oxidation-mediated pigment stabilization, besides pigment profiles. An effect of leaf removal treatments on vitisins was previously reported by other authors [38]. The meta-analysis conducted by VanderWeide [3] reported that early leaf removal altered secondary metabolites (e.g., anthocyanins and total polyphenols) to a greater extent than soluble solids, the mean increase observed was not statistically significant, mainly due to cultivar variability, as well as the differences in the analytical protocols adopted in the different studies. Kemp et al. [39] reported increased proanthocyanin levels derived from early leaf removal in Pinot noir. These results were confirmed for Pinot noir by Verdenal and colleagues, who found an increase on total polyphenols and total anthocyanins [40]. Verdenal et al. [33] carried out another extensive survey on the effect of early leaf removal on five different cultivars, both red and white, and observed relevant differences in the responses among cultivars. However, due to preflowering leaf removal, the red wines were often preferred for their color. Wines from Dalmatian cv. Trnjak had higher anthocyanin concentration when obtained upon early leaf removal [41]. Increase in anthocyanin and total phenols was also observed in Carignan and Graciano wines as an effect of early defoliation [5]. Basal leaf removal increased total amount of anthocyanins, flavonoids, polyphenols and color intensity in wines from the Sicilian cultivar Nero d'Avola; although, the effect strongly depended on the time of grape harvesting [24]. Torres et al. [9] recently reported that early defoliation combined with shoot thinning led to Cabernet Sauvignon wines with higher total polyphenols; shifts in the profiles of anthocyanins, flavonols, flavan3-ols and proanthocyanidins were also observed. However, Guidoni et al. [4] reported an improvement in Barbera skin anthocyanin and polyphenol composition only in the coolest and rainiest year - the least suitable weather for Barbera ripening. Cluster direct exposure to sunlight increases cluster temperature, frequently causing berry withering or sunburn, and modifying the accumulation of some berry quality components. Therefore, in microclimatic conditions, unfavorable for exposed vineyards, leaf removal may improve grape health and quality [4].

\subsection{Wine Volatile Composition}

Figure 2 shows the effect of early leaf removal (DN, DS and DNS) on the concentration of the volatile composition of Aglianico wine. They have been grouped into several groups: alcohols, C6 compounds, terpenes + C13 norisoprenoids, esters + acetates, volatile acids, aldehydes, volatile phenols, and lactones. Early leaf removal induced significant changes in the concentration of four groups of compounds (C6 compounds, terpenes + C13 norisoprenoids, volatile acids, and volatile phenols) increasing their concentration with respect to the control. In the same way, a trend to increase the concentration on the other groups of compounds studied was observed when early leaf removal was applied in Aglianico. Vitis vinifera L. cv. Nero d'Avola, submitted to early defoliation treatment, showed significantly higher amounts of most volatile constituents, such as acids, furfural aldehydes and C13-norisoprenoids, than did the control ones [24]. 


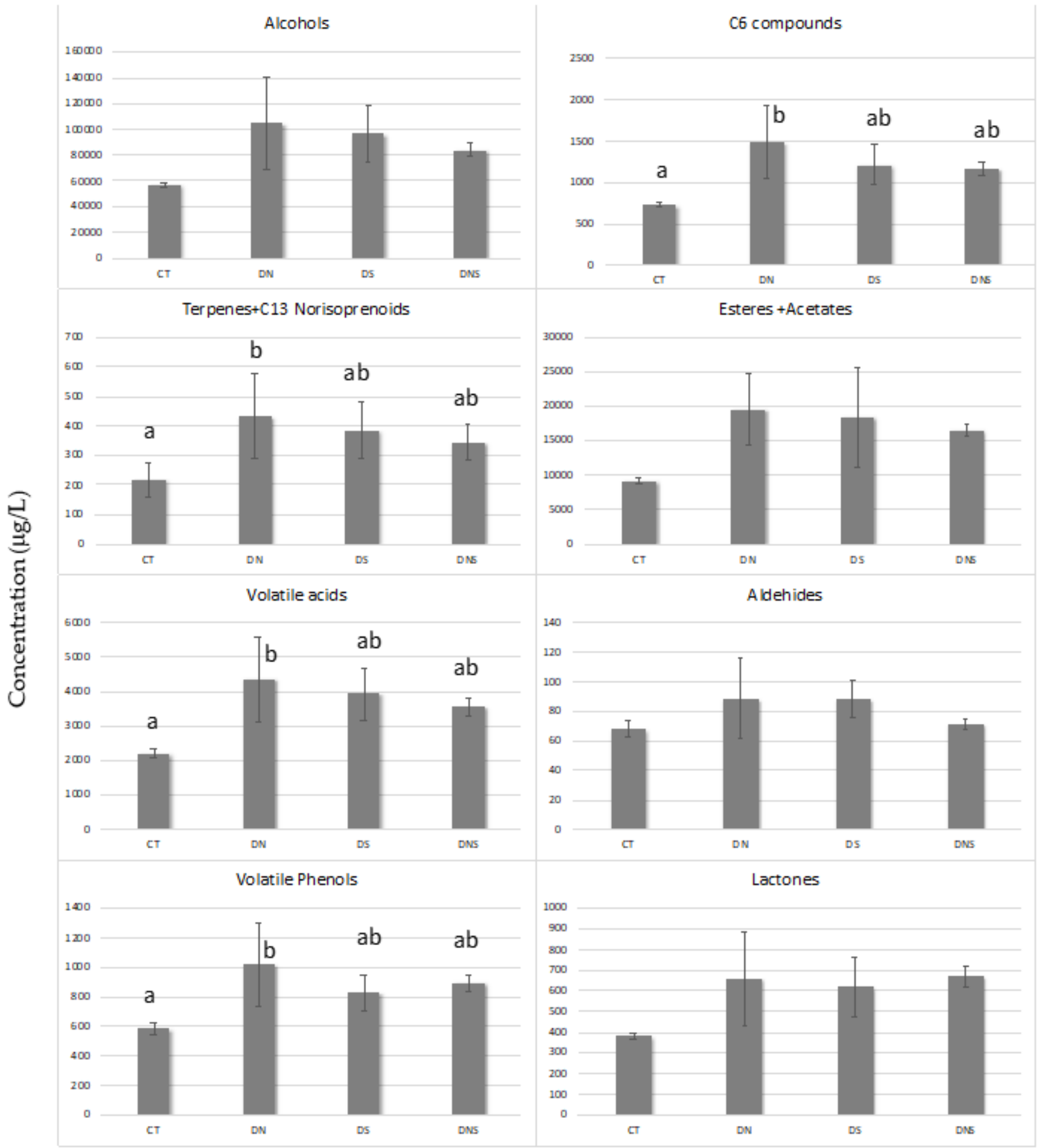

Figure 2. Total volatile concentration $(\mathrm{mg} / \mathrm{L})$ by families of Aglianico red wines obtained by early basal leaf removal treatments. Differences letters indicate significant differences for Tukey's test at $p<0.05$. CT-control; DN-defoliation on the north side of the canopy; DS-defoliation on the south side of the canopy; DNS-defoliation on both sides of the canopy.

Additionally, slight variations of volatiles by the effect of early defoliation were observed based on the canopy side involved. Thus, Aglianico wines from early leaf removal in the north side (DN) showed a tendency to increase the concentration of all volatile families of compounds with exception of lactones, which was higher when defoliation was made in both the north and the south side of the canopy (DNS). According to these 
results, early leaf removal induced the increase in the concentration of all families of volatile compounds, quantified in Tempranillo wine from Southern Spain, with exception of lactones [42]. Other researchers showed that leaf removal induced an increase in grape and wine volatile composition $[26,43]$.

Table 5 presents the influence of the early leaf removal treatment (DS, DN and DNS) and control on the individual volatile compounds identified and quantified by GC-MS in Aglianico wines (expressed as $\mu \mathrm{g} / \mathrm{L}$ ); one-way ANOVA results, by treatment, are also shown. A total of 37 volatile compounds were identified and quantified by GC-MS in Aglianico wines. Alcohols were the largest group of volatile compounds accounting for all leaf removal and control treatments with 9 compounds quantified $(>78 \%$ of the total volatile concentration), followed by ethyl esters + acetates, represented by 9 compounds ( $>13 \%$ of total volatile concentration).

Results of the ANOVA showed the effect of treatments on $37.8 \%$ ( 14 out 37 compounds) of the volatiles identified and quantified. Leaf removal treatments led to wines with the significant highest concentrations of 13 volatile compounds vs. control, mainly ethyl esters and acetates. Thus, early leaf removal induced the increase of three alcohols (3-methyl-1pentanol, 2,3-butanediol and 1-octanol) one C6 compound (1-hexanol), one terpene (E-8hydroxy linalool), four esters + acetates (hexyl acetate, diethyl succinate, diethyl malate and ethyl myristate), three volatile acids (octanoic, nonanoic and decanoic acids) and one volatile phenol (4-vinylphenol). From the phenol volatiles group, 4-ethylphenol was not identified when early leaf removal was applied. The increase in acetates concentration when early defoliation was applied was also observed in Tempranillo wines from Northern Spain [26]. In the same work, it was observed that early leaf removal induced a significant reduction in C6 compounds. However, Tempranillo wine from Southern Spain showed higher concentration of C6 compounds when pre-bloom basal leaf removal was applied vs. control [42]. In this study, according with our results, the highest concentration was observed for 1-hexanol. In Istrian Malvasia wine, the effect of early defoliation was higher than defoliation at véraison, where wines from pre-bloom defoliation increased ethyl esters and higher alcohols concentration [44].

On the other hand, the effects of defoliation depended on amount and type of leaves removed and on defoliation timing [45]. The grapevine canopy consists of leaves of different ages, which are subjected to variable light intensities during the entire growth season, affected by photosynthesis, transpiration and microclimate [46]. In fact, the high light intensity and temperature induced by excessive defoliations may reduce the skin color in red cultivars [47]; while several authors have observed a positive effect of light penetration on grape quality $[24,26,44)$, the negative influence on vine metabolism could be due to the effect of high temperatures in some semiarid regions affecting to wine aroma and color [42].

The effect of early defoliation based on the canopy side involved was observed on individual compounds. Thus, Aglianico wines from early leaf removal on the north side (ND) showed a trend to increase the mayor number of compounds quantified, with exceptions of 2-methyl-1-propanol, 3-methyl-1-propanol, 3-oxo-7,8-dihydro-a-ionol, isoamyl acetate and hexyl acetate, which were higher when early leaf removal was made on the south side (SD) of the canopy. Moreover, three compounds (2,3-butanediol, 4-ethylguaiacol and butyrolactone) showed a trend to increase their concentration when early defoliation was performed on both sides of the canopy (DNS). In this sense, it is known that the sunlight exposure affects the cluster temperature, influencing the degradation of malic acid, increasing the sugar/acid ratio and significantly affecting the levels of varietal aroma compounds in grape berries [48]. 
Table 5. Concentration $(\mu \mathrm{g} / \mathrm{L})$ of wine volatiles from Aglianico red wines obtained by early basal leaf removal treatments.

\begin{tabular}{|c|c|c|c|c|c|c|c|c|c|}
\hline \multirow{2}{*}{ Compounds } & \multicolumn{2}{|c|}{ CT } & \multicolumn{2}{|c|}{ DN } & \multicolumn{2}{|c|}{ DS } & \multicolumn{2}{|c|}{ DNS } & \multirow{2}{*}{ Sig } \\
\hline & Mean & SD & Mean & SD & Mean & SD & Mean & SD & \\
\hline \multicolumn{10}{|c|}{ Alcohols } \\
\hline 2-methyl-1-propanol & 998.2 & 15.5 & 1744.4 & 650.6 & 1851.1 & 493.5 & 1810.7 & 73.5 & ns \\
\hline 2+3-methyl-1-butanol & $25,880.4$ & 696.8 & $49,220.0$ & $18,132.0$ & $45,350.7$ & $11,548.9$ & $38,843.5$ & 2471.5 & ns \\
\hline 3-methyl-1-pentanol & $32.1 \mathrm{a}$ & 1.4 & $54.8 \mathrm{ab}$ & 16.5 & $62.7 \mathrm{~b}$ & 8.1 & $60.4 \mathrm{~b}$ & 2.6 & $*$ \\
\hline 2,3-butanediol & $108.8 \mathrm{a}$ & 4.0 & $273.8 \mathrm{~b}$ & 100.3 & $301.7 \mathrm{~b}$ & 53.2 & $360.1 \mathrm{~b}$ & 48.4 & $* *$ \\
\hline 1-octanol & $158.5 \mathrm{a}$ & 9.8 & $334.7 \mathrm{~b}$ & 91.1 & $302.8 \mathrm{ab}$ & 64.9 & $290.1 \mathrm{ab}$ & 20.3 & $*$ \\
\hline 3-methylthiopropanol & 222.3 & 15.8 & 429.5 & 163.9 & 353.0 & 114.3 & 300.9 & 21.9 & ns \\
\hline Benzyl alcohol & 24.3 & 1.2 & 46.1 & 17.1 & 43.7 & 11.3 & 38.5 & 2.7 & ns \\
\hline 2-phenylethanol & $29,468.0$ & 912.4 & $52,814.4$ & $16,824.5$ & $48,537.4$ & $10,200.5$ & $42,152.7$ & 2555.7 & ns \\
\hline \multicolumn{10}{|c|}{ C6 compounds } \\
\hline 1-hexanol & $669.0 \mathrm{a}$ & 30.1 & $1366.4 \mathrm{~b}$ & 390.2 & $1109.2 \mathrm{ab}$ & 212.9 & $1071.1 \mathrm{ab}$ & 68.1 & * \\
\hline E-3-hexenol & 25.2 & 2.0 & 46.3 & 17.1 & 42.2 & 18.4 & 33.9 & 8.2 & ns \\
\hline 2-ethyl-hexanol & 40.8 & 2.7 & 68.5 & 31.1 & 64.2 & 15.3 & 63.4 & 5.9 & ns \\
\hline \multicolumn{10}{|c|}{ Terpenes + C13 Norisoprenoids } \\
\hline a-terpineol & 39.5 & 5.9 & 79.1 & 25.1 & 67.0 & 13.9 & 73.1 & 11.4 & ns \\
\hline E-8-hydroxy linalool & $57.3 \mathrm{a}$ & 8.5 & $184.3 \mathrm{~b}$ & 45.4 & $166.5 \mathrm{~b}$ & 39.4 & $143.4 \mathrm{~b}$ & 11.6 & $* *$ \\
\hline 3-hydroxy-7,8-dihydro-b-ionol & 57.7 & 27.8 & 85.9 & 49.7 & 51.2 & 0.9 & 51.9 & 13.7 & ns \\
\hline 3-oxo-7,8-dihydro-a-ionol & 62.0 & 15.4 & 83.9 & 21.3 & 100.2 & 40.3 & 74.6 & 24.9 & ns \\
\hline \multicolumn{10}{|c|}{ Esters + Acetates } \\
\hline Isoamylacetate & 116.4 & 15.8 & 200.4 & 38.8 & 279.8 & 45.5 & 178.4 & 15.1 & ns \\
\hline Ethyl hexanoate & 140.5 & 28.8 & 268.3 & 88.2 & 220.8 & 16.0 & 208.5 & 30.0 & ns \\
\hline Hexyl acetate & $0.0 \mathrm{a}$ & 0.0 & $0.0 \mathrm{a}$ & 0.0 & $56.8 \mathrm{~b}$ & 22.8 & $53.5 \mathrm{~b}$ & 14.2 & $* *$ \\
\hline Ethyl lactate & 812.4 & 37.4 & 1708.7 & 676.4 & 1413.6 & 426.4 & 1059.4 & 49.0 & ns \\
\hline Ethyl octanoate & 77.8 & 1.0 & 127.9 & 42.3 & 113.1 & 16.1 & 93.7 & 19.9 & ns \\
\hline Diethyl succinate & $6128.4 \mathrm{a}$ & 373.3 & $13,403.3 \mathrm{~b}$ & 3146.3 & $10,634.5 \mathrm{ab}$ & 1543.2 & $11,683.6 \mathrm{~b}$ & 503.5 & $* *$ \\
\hline 2-phenylethylacetate & 32.7 & 3.9 & 62.0 & 20.8 & 56.7 & 9.5 & 59.1 & 3.4 & ns \\
\hline Diethyl malate & $1701.6 \mathrm{a}$ & 61.9 & $3484.5 \mathrm{~b}$ & 1019.1 & $2866.3 \mathrm{ab}$ & 580.8 & $2882.1 \mathrm{ab}$ & 191.0 & * \\
\hline Ethyl myristate & $101.5 \mathrm{a}$ & 3.0 & $240.8 \mathrm{~b}$ & 53.7 & $192.5 \mathrm{~b}$ & 19.8 & $221.9 \mathrm{~b}$ & 16.3 & $* *$ \\
\hline \multicolumn{10}{|c|}{ Volatile acids } \\
\hline Isobutyric acid & 107.5 & 4.4 & 209.8 & 74.1 & 208.5 & 57.0 & 196.5 & 24.4 & ns \\
\hline 2+3-methylbutanoic acid & 214.9 & 13.1 & 393.7 & 156.0 & 347.1 & 122.9 & 269.3 & 34.4 & ns \\
\hline Hexanoic acid & 317.1 & 10.5 & 562.3 & 172.4 & 536.1 & 119.3 & 439.2 & 26.4 & ns \\
\hline Octanoic acid & $597.3 \mathrm{a}$ & 30.4 & $1124.4 \mathrm{~b}$ & 241.6 & $1041.5 \mathrm{~b}$ & 148.3 & $787.5 \mathrm{ab}$ & 35.0 & $* *$ \\
\hline Nonanoic acid & $687.7 \mathrm{a}$ & 25.0 & $1474.3 \mathrm{~b}$ & 393.7 & $1312.9 \mathrm{~b}$ & 213.0 & $1456.5 \mathrm{~b}$ & 88.8 & $* *$ \\
\hline Decanoic acid & $197.3 \mathrm{a}$ & 19.8 & $437.2 \mathrm{~b}$ & 117.9 & $366.1 \mathrm{ab}$ & 59.6 & $307.8 \mathrm{ab}$ & 32.9 & * \\
\hline Hexadecanoic acid & 79.9 & 22.4 & 151.6 & 71.5 & 127.0 & 49.1 & 102.1 & 2.9 & ns \\
\hline \multicolumn{10}{|c|}{ Aldehydes } \\
\hline Phenylethanal & 67.9 & 5.3 & 88.8 & 27.3 & 88.7 & 13.0 & 71.5 & 3.2 & ns \\
\hline \multicolumn{10}{|c|}{ Volatile Phenols } \\
\hline 4-ethylguaiacol & $51.3 \mathrm{a}$ & 3.1 & 37.3 & 7.4 & 41.2 & 13.3 & 48.4 & 6.4 & ns \\
\hline 4-ethylphenol & $118.1 \mathrm{~b}$ & 7.9 & $0.0 \mathrm{a}$ & 0.0 & $0.0 \mathrm{a}$ & 0.0 & $0.0 \mathrm{a}$ & 0.0 & $* * *$ \\
\hline 4-vinylguaiacol & 40.6 & 4.2 & 70.1 & 40.6 & 76.3 & 19.1 & 67.7 & 4.2 & ns \\
\hline 4-vinylphenol & $375.1 \mathrm{a}$ & 28.9 & $910.6 \mathrm{~b}$ & 237.6 & $711.2 \mathrm{ab}$ & 84.8 & $773.4 \mathrm{~b}$ & 45.4 & $* *$ \\
\hline \multicolumn{10}{|c|}{ Lactones } \\
\hline Butyrolactone & 382. & 14.7 & 654.1 & 227.7 & 619.9 & 145.8 & 667.2 & 47.8 & ns \\
\hline
\end{tabular}

Different letters indicate significant differences for Tukey's test at $p<0.05$. Signs: ${ }^{*}$ - significance at $p<0.05$; ** - significance at $p<0.01$; *** — significance at $p<0.001$; ns—not significant; CT—control; DN—defoliation on the north side of the canopy; DS - defoliation on the south side of the canopy; DNS — defoliation on both sides of the canopy. 


\subsection{Sensory Analysis}

The effect of early leaf removal on Aglianico wines was evaluated by sensory descriptive analysis. The sensory profile of Aglianico wines was characterized by 27 descriptors belonging to odor (17 descriptors), taste ( 9 descriptors) and total value. The frequency (F), intensity (I) and geometric mean (GM) of the different descriptors are shown in Table 6.

Table 6. Relative intensity ( $\%$ I), relative frequency ( $\%$ F) and geometric mean ( $\% \mathrm{GM})$ determined for the sensory descriptors of Aglianico red wines obtained by early basal leaf removal treatments.

\begin{tabular}{|c|c|c|c|c|c|c|c|c|c|c|c|c|c|}
\hline \multirow{2}{*}{\multicolumn{2}{|c|}{ Descriptors }} & \multicolumn{3}{|c|}{$\mathrm{CT}$} & \multicolumn{3}{|c|}{ DN } & \multicolumn{3}{|c|}{ DS } & \multicolumn{3}{|c|}{ DNS } \\
\hline & & $\% \mathrm{I}$ & $\% \mathrm{~F}$ & $\% G M$ & $\% \mathbf{I}$ & $\% \mathrm{~F}$ & $\%$ GM & $\% \mathbf{I}$ & $\% \mathrm{~F}$ & $\%$ GM & $\% \mathbf{I}$ & $\% \mathrm{~F}$ & \%GM \\
\hline \multirow{17}{*}{ Odor } & Intensity & 63.5 & 100.0 & 79.7 & 64.5 & 100.0 & 80.3 & 67.0 & 100.0 & 81.8 & 70.0 & 100.0 & 83.7 \\
\hline & Quality & 54.5 & 85.0 & 68.1 & 63.5 & 100.0 & 79.7 & 61.5 & 100.0 & 78.4 & 71.0 & 100.0 & 84.3 \\
\hline & Fruity & 50.5 & 90.0 & 67.2 & 52.0 & 90.0 & 68.4 & 45.0 & 85.0 & 61.7 & 54.5 & 85.0 & 68.1 \\
\hline & Floral & 19.0 & 50.0 & 30.8 & 26.5 & 65.0 & 41.5 & 24.5 & 65.0 & 39.9 & 26.0 & 70.0 & 42.6 \\
\hline & Herbaceous & 25.0 & 55.0 & 37.1 & 23.5 & 70.0 & 40.5 & 19.5 & 70.0 & 36.7 & 19.0 & 70.0 & 36.4 \\
\hline & Red fruts & 46.5 & 85.0 & 62.8 & 49.0 & 90.0 & 66.4 & 55.0 & 100.0 & 74.1 & 61.0 & 95.0 & 76.1 \\
\hline & Spicy & 31.5 & 70.0 & 46.9 & 38.5 & 85.0 & 57.2 & 38.0 & 90.0 & 58.4 & 43.5 & 90.0 & 62.5 \\
\hline & Phenolic & 21.5 & 60.0 & 35.8 & 25.0 & 60.0 & 38.4 & 27.5 & 70.0 & 43.9 & 26.0 & 55.0 & 37.8 \\
\hline & Mint & 3.5 & 5.0 & 4.2 & - & - & - & 2.5 & 5.0 & 3.5 & - & - & - \\
\hline & Balsamic & 5.5 & 10.0 & 7.4 & - & - & - & 2.5 & 5.0 & 3.5 & - & - & - \\
\hline & Earthy & 3.0 & 5.0 & 3.9 & - & - & - & 2.5 & 5.0 & 3.5 & - & - & - \\
\hline & Ripe fruit & 4.5 & 5.0 & 4.7 & - & - & - & 3.0 & 5.0 & 3.9 & - & - & - \\
\hline & Liquor & 2.0 & 5.0 & 3.2 & - & - & - & - & - & - & 8.5 & 10.0 & 9.2 \\
\hline & Peper & - & - & - & 2.5 & 5.0 & 3.5 & - & - & - & - & - & - \\
\hline & Raisin & 2.5 & 5.0 & 3.5 & 1.0 & 5.0 & 2.2 & 5.0 & 10.0 & 7.1 & - & - & - \\
\hline & Vanilla & - & - & - & - & - & - & - & - & - & 5.5 & 10.0 & 7.4 \\
\hline & Licorice & - & - & - & - & - & - & 1.0 & 5.0 & 2.2 & 4.5 & 10.0 & 6.7 \\
\hline \multirow{10}{*}{ Taste } & Quality & 54.5 & 95.0 & 71.9 & 53.0 & 90.0 & 69.1 & 51.5 & 90.0 & 68.0 & 63.0 & 95.0 & 77.4 \\
\hline & Sweetness & 20.0 & 50.0 & 31.6 & 22.5 & 55.0 & 35.2 & 26.0 & 65.0 & 41.0 & 30.0 & 70.0 & 45.8 \\
\hline & Saltiness & 17.0 & 60.0 & 31.9 & 18.5 & 80.0 & 38.5 & 22.5 & 80.0 & 42.4 & 19.5 & 50.0 & 31.2 \\
\hline & Acidity & 46.5 & 90.0 & 64.7 & 41.5 & 80.0 & 57.6 & 44.0 & 90.0 & 62.9 & 44.0 & 95.0 & 64.7 \\
\hline & Bitterness & 41.0 & 100.0 & 64.0 & 41.0 & 100.0 & 64.0 & 37.0 & 95.0 & 59.1 & 36.5 & 95.0 & 58.9 \\
\hline & Astringency & 53.0 & 95.0 & 70.9 & 59.0 & 100.0 & 76.8 & 53.0 & 100.0 & 72.6 & 51.0 & 95.0 & 73.6 \\
\hline & Body & 49.5 & 90.0 & 66.7 & 52.5 & 95.0 & 70.6 & 53.0 & 100.0 & 72.8 & 60.0 & 100.0 & 77.5 \\
\hline & Persistence & 54.0 & 100.0 & 73.5 & 52.0 & 95.0 & 70.3 & 54.0 & 100.0 & 73.5 & 64.0 & 100.0 & 80.0 \\
\hline & Balanced & - & - & - & - & - & - & 3.0 & 5.0 & 3.9 & 4.0 & 5.0 & 4.5 \\
\hline & $\begin{array}{c}\text { Total } \\
\text { quality }\end{array}$ & 59.0 & 100.0 & 76.8 & 61.0 & 100.0 & 78.1 & 58.0 & 100.0 & 76.1 & 67.5 & 100.0 & 82.1 \\
\hline
\end{tabular}

CT-control; DN—defoliation on the north side of the canopy; DS—defoliation on the south side of the canopy; DNS-defoliation on both sides of the canopy.

From odor descriptors, the most relative intensities were showed by odor intensity $(>63 \%)$, odor quality $(>54 \%)$, fruity $(>45 \%)$ and red fruits $(>46 \%)$, where wines from DNS treatments showed the highest values $(70,71,54$ and 71 , respectively). With respect to taste descriptors, DNS wines showed the highest relative intensity values for quality $(63 \%)$, body $(60 \%)$ and persistence $(64 \%)$. The wines from early defoliation on the north side (DN) were the most astringent.

With respect to relative frequency, wines from early leaf removal, mainly DNS, exhibited the highest values ( $>55 \%$ ) of eight odor descriptors (intensity, quality, fruity, floral, herbaceous, red fruit, spicy and phenolic). An increase in fruity and floral odor was observed in Tempranillo wine when early defoliation was applied [42]. In taste, all descriptors showed relative frequency $>50 \%$ with exception to balanced descriptor. In general, the most frequency of these descriptors were found for wines from DNS treatment, with the exceptions of salt (DN and DS) and bitter (CT and DN). Pinot noir wines from the preflowering defoliation treatment were described as less fruity and more herbaceous in comparison 
with those of the other treatments. In terms of mouth feel, these tended to have more volume and intensity [33].

In respect to relative intensity of global quality, wines from the DNS treatment showed the highest value $(67.5 \%)$ and all wines exhibited $100 \%$ relative frequency.

The intensity (I) and frequency (F) of each attribute permitted the geometric mean (GM) to be obtained. GM (\%) was calculated for each descriptor as a square root of the product between the relative intensity and relative frequency. In this study, descriptors with GM > 30\% were considered the highest contributors. Eight sensory attributes with GM $>30 \%$ defined the aroma of Aglianico wines. In taste, eight attributes showed GM $>30 \%$. Odor and taste profiles in relation to GM (\%) are showed in Figure 3. The highest \% GM of total value was also reached by wines from DNS treatment. Defoliation enhances grape quality $[49,50]$ by improving berry color and flavor [51], total anthocyanin and phenolic concentrations, color intensity and sensory quality of wines [52]. The wine tasting confirmed the enhancement of wine aromas and taste through significant changes in the concentration of volatile compounds, according to results observed by other researchers $[23,30]$. These results explained that in spite of the effects of defoliation on wine volatiles, results of sensory analysis depend on perception of the interactions among volatile compounds and on the threshold values of each compound [53].

(a) Odour descriptors $>30 \%$ GM

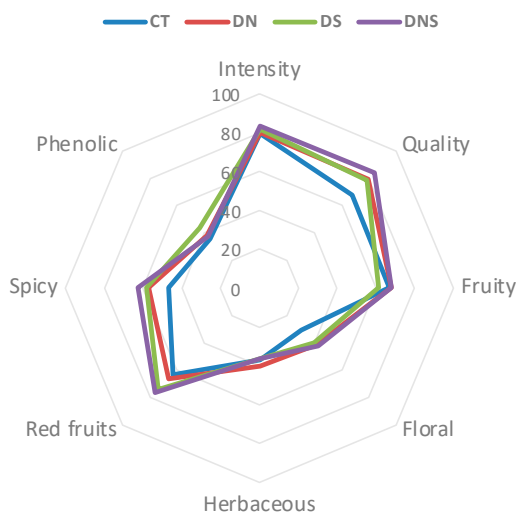

(b) Taste descriptors > $30 \%$ GM

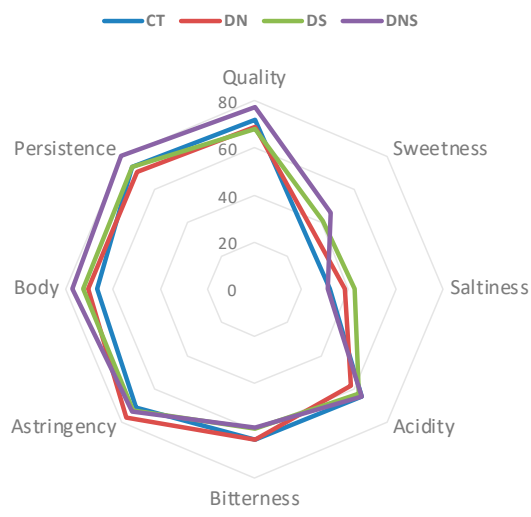

Figure 3. Odor (a) and taste (b) profiles (\% GM) of Aglianico red wines obtained by early basal leaf removal treatments. CT-control; DN—defoliation on the north side of the canopy; DS-defoliation on the south side of the canopy; DNS-defoliation on both sides of the canopy. 


\section{Materials and Methods}

\subsection{Vineyard, Leaf Removal Treatment and Vinification}

Early basal leaf removal experiments were conducted in commercial Aglianico (Vitis vinifera L.) vineyards situated in Apulia region in Southern Italy (CGDO Castel del Monte area) during the 2018 season (Corato, lat: $41^{\circ} 04^{\prime} 35^{\prime \prime} \mathrm{N}$; long. $16^{\circ} 21^{\prime} 46^{\prime \prime} \mathrm{E} 354 \mathrm{~m}$ a.s.1.). Approximately 15 days before flowering (middle of May BBCH 57), the following 4 early leaf removal treatments (leaf removal of the basal part of the shoot up to the last cluster) were manually applied: CT-no leaf removal or non-defoliated vines, where all basal leaves were retained in each shoot; DS- $100 \%$ of fruit-zone leaves on each shoot were removed from the south canopy side; DN-100\% of fruit-zone leaves on each shoot were removed from the north canopy side; DNS-100\% removal of fruit-zone leaves on both the north and the south sides of the canopy.

Six adjacent rows were selected to set up a randomized complete block design, with two rows as a block. Within each 2 rows, 3 sections of 18 vines per plot were tagged and randomly assigned to the leaf removal treatments, imposed with 54 vines for each treatment.

Per trial, about $80 \mathrm{~kg}$ of grapes at commercial maturity were immediately submitted to winemaking at the experimental winery of Bari University according to Gambacorta et al. [54] protocol, with some modifications. In brief, grapes of each trial were de-stemmed, crushed and transferred in $100 \mathrm{~L}$ vertical stainless steel vats, and potassium metabisulphite $(6 \mathrm{~g} / 100 \mathrm{~kg})$, yeast (Saccharomyces cerevisiae var. Bayanus, Mycoferm CRU05, 20 g/100 kg) and yeast activator (preparation based on ammonium sulphate, diammonium phosphate, chemically inert filter and as dispersing agent, Vitamin B1, Enovit, AEB, Italy) were added. Nine days of maceration were applied with two punch-downs per day. When maceration was concluded, free-run wine was recovered, and pomace was gently pressed for obtaining press-run wine using $80 \mathrm{~L}$ stainless steel hydro press. The two wine fractions were blended after 2 weeks of racking was performed to eliminate gross lees. Wine was bottled after 6 months, without any treatment. Three replications of wines were analyzed.

\subsection{Enological Parameters}

Sugar concentration, $\mathrm{pH}$, ethanol, titratable acidity, citric, tartaric, malic and acetic acids and total polyphenol index (TPI) in wines were analyzed in triplicate by using a Foss WineScan FT 120, as described by the manufacturer (Foss, Hillerød, Denmark).

\subsection{Analysis of Polyphenols}

The phenolic composition of wines was analyzed by spectrophotometry as described by Di Stefano and Cravero [55]. Color intensity (CI), given by the sum of absorbances at 420,520 and $620 \mathrm{~nm}$, and hue (ratio of absorbances $420 \mathrm{~nm} / 520 \mathrm{~nm}$ ) were analyzed by the Glories method [56].

Antioxidant activity (AA) was assessed using ABTS [2,2'-azino-bis(3-ethylbenzothiazoline6-sulfonic acid)] assay [57], and results were expressed as $\mu \mathrm{M}$ Trolox equivalent antioxidant.

The polyphenolic profile of wines was determined by LC-MS/MS. A Dionex Ultimate 3000 LC System (Thermo Fisher Scientific, MA, USA) comprising a quaternary pump, an autosampler, a column oven and a DAD detector. The LC system was interfaced with a LTQ Velos Pro Linear Ion Trap mass spectrometer (Thermo Fisher Scientific, MA, USA) through a HESI interface. The samples, previously filtered on $0.22 \mu \mathrm{m}$ regenerated cellulose membrane, were injected into a C18 Hypersil GOLD aQ column $(100 \mathrm{~mm} \times 2.1 \mathrm{~mm} \times 1.9 \mu \mathrm{m}$, Thermo Fisher Scientific, MA, USA). The mobile phase was constituted by water acidified with $10 \%$ formic acid (A) and acetonitrile with $0.1 \%$ of formic acid (B). The flow rate of the mobile phase was $0.3 \mathrm{~mL} \mathrm{~min}^{-1}$, and the injection volume was $5 \mu \mathrm{L}$. A gradient-elution program was as follows: linear gradient from $2 \% \mathrm{~B}$ to $70 \% \mathrm{~B}, 0-20 \mathrm{~min}$, isocratic of $70 \% \mathrm{~B}$, 20-24 min, linear gradient from $70 \%$ B to $2 \%$ B, 24-34 min. The mass spectrometer conditions were as follows: spray voltage $+2.5 \mathrm{kV}$, sheath gas 30 psi, auxiliary gas flow 15 arbitrary units, capillary temperature $320^{\circ} \mathrm{C}$, capillary voltage $+95 \mathrm{~V}$, tube lens $+170 \mathrm{~V}$, skimmer $+38 \mathrm{~V}$, and heater temperature $280^{\circ} \mathrm{C}$. Samples were analyzed in MS/MS in 
data dependent mode, with a full scan in the range 150-1200 m/z, mass spectrometry data were acquired in both positive and negative ion mode. Malvidin-3-O-glucoside, gallic acid, caftaric acid, quercetin-3-glucuronide, miricetin, quercetin and catechin were identified by comparing elution times, molecular ions, and MS/MS fragmentation patterns of the experimental spectra with those obtained by pure standards, whereas other compounds were tentatively identified by data reported from the literature [58-61]. Quantitative analysis was carried out using a diode array detector at wavelengths $280 \mathrm{~nm}$ (flavanols), $330 \mathrm{~nm}$ (phenolic acids), $350 \mathrm{~nm}$ (flavonols) and anthocyanins (520 nm). Calibration curves of malvidin-3-glucoside (for anthocyanins), gallic acid (for phenolic acids) and quercetin (for flavanols and flavonols) were built ( $\mathrm{R} 2=0.9975, \mathrm{R} 2=0.9988, \mathrm{R} 2=0.9974$ respectively). The analyses were carried out in triplicate and results were expressed in $\mathrm{mg} \mathrm{L}^{-1}$.

\subsection{Wine Volatile Composition}

In a $10 \mathrm{~mL}$ culture tube, $8 \mathrm{~mL}$ of wine, $3 \mu \mathrm{g}$ of internal standard (4-nonanol) and a magnetic stir bar $(22.2 \mathrm{~mm} \times 4.8 \mathrm{~mm})$ were added. Volatiles were extracted by stirring the sample with $400 \mathrm{~mL}$ of dichloromethane, as described by Coelho et al. [62]. After cooling at $0{ }^{\circ} \mathrm{C}$ for $10 \mathrm{~min}$, the magnetic stir bar was removed, the organic phase was detached by centrifugation $\left(5118 \mathrm{~g}, 5 \mathrm{~min}, 4^{\circ} \mathrm{C}\right)$, and the extract was recovered into a vial, using a Pasteur pipette. The aromatic extract $\left(200 \mu \mathrm{g} \mathrm{L}^{-1}\right)$ was dried with anhydrous sodium sulphate and placed in a new vial. Volatile compounds were extracted from each of the wines in triplicate.

Gas chromatographic analysis of volatile compounds was performed using an Agilent GC 6890 N chromatograph (Agilent Technologies, Palo Alto, CA, USA) coupled to mass spectrometer Agilent 5975C. A $1 \mu \mathrm{L}$ injection was made into a capillary column, coated with CP-Wax $52 \mathrm{CB}(50 \mathrm{~m} \times 0.25 \mathrm{~mm}$ i.d., $0.2 \mu \mathrm{m}$ film thickness, Chrompack). The temperature of the injector was programmed from $20^{\circ} \mathrm{C}$ to $250{ }^{\circ} \mathrm{C}$, at $180^{\circ} \mathrm{C} \mathrm{min}{ }^{-1}$. The oven temperature was held at $40{ }^{\circ} \mathrm{C}$ for $5 \mathrm{~min}$, then it was programmed to rise from $40{ }^{\circ} \mathrm{C}$ to $250{ }^{\circ} \mathrm{C}$, at $3{ }^{\circ} \mathrm{C} \mathrm{min}{ }^{-1}$, then it was held for $20 \mathrm{~min}$ at $250^{\circ} \mathrm{C}$, and finally it was programmed to go from $250{ }^{\circ} \mathrm{C}$ to $255^{\circ} \mathrm{C}$ at $1^{\circ} \mathrm{C} \mathrm{min}^{-1}$. The carrier gas was helium N60 (Air Liquide) at $103 \mathrm{kPa}$, which corresponds to a linear speed of $180 \mathrm{~cm} \mathrm{~s}^{-1}$ at $150{ }^{\circ} \mathrm{C}$. The detector was set to electronic impact mode $(70 \mathrm{eV})$, with an acquisition range from 29 to $360 \mathrm{~m} / \mathrm{z}$, and an acquisition rate of $610 \mathrm{~ms}$.

The compounds were identified using WSearch Free Software, by comparing mass spectra and retention indices with those of pure standard compounds. Pure standard compounds were purchased from Sigma-Aldrich (Darmstadt, Germany) with purity higher than $98 \%$. Semi-quantitative data were obtained by calculating the relative peak area in relation with internal standard (4-nonanol).

\subsection{Sensory Analysis}

The sensory analysis was performed by 10 panelists from Rias Baixas AOC (Galicia, Spain) sensory panel, 4 males and 6 females, with ages between 35 and 60 years old. All the judges were experienced tasters and all of them have previously participated in similar studies. In accordance with ISO Norm 8589, the sensory analysis was performed in a professional-standard room. The evaluation was carried out using the QDA methodology [63] to establish descriptors of the wines. The terms, balance, odor quality, taste quality and total quality, normally used by the Rias Baixas AOC panel, were added to the sensory analysis. Odor quality and taste quality were defined by the panel as absence of defects; total quality was defined as the global perception of the wines (odor and taste); balance was defined as harmony, the integration of acidity, sugar, alcohol and bitter. A constant sample volume of $30 \mathrm{~mL}$ of each wine was evaluated in wine taster glasses at $12{ }^{\circ} \mathrm{C}$. During the analysis, the judges smelled and tasted the samples, and the perceived descriptors were indicated. Then, they scored the intensity of each attribute using a 10-point scale, where 10 indicated a very high intensity. The relative frequency $(\mathrm{F})$, relative intensity $(\mathrm{I})$ and geometric mean (GM) of the different descriptors were calculated for each wine. GM was calculated 
as the square root of the product between I and F, i.e., GM $(\%)=\sqrt{ }(I \times F) \times 100$, where I corresponds to the sum of the intensities given by the panel for a descriptor, divided by the maximum possible intensity for this descriptor; $\mathrm{F}$ is the number of times that the descriptor was mentioned, divided by the maximum number of times that it could be mentioned.

The descriptors were classified for each wine by using the GM according to the International Organization for Standardization-ISO Norm 11,035-which made it possible to eliminate the descriptors whose geometric means were relatively low. This method allowed us to consider descriptors which were rarely mentioned but which were very important in terms of the perceived intensity, and descriptors with a low perceived intensity but which are mentioned often [64].

\subsection{Statistical Analysis}

All data were analyzed using the XLSTAT-Pro 2017 statistical package (Addinsoft, Paris, France). A one-way ANOVA was used to evaluate the differences among treatments. The multiple comparison among treatments were calculated according to the least significant difference from Tukey's test. Principal components analysis (PCA) was performed using Origin Pro 2021 (OriginLab, Northampton, MA, USA).

\section{Conclusions}

Early defoliation is a viticulture practice aimed at regulating yield components and improving grape quality. The effect of vines defoliation on Aglianico wine quality was studied. Early basal leaf removal allowed us to modulate the volatile and phenolic compounds and, therefore, the sensory properties of wines. Defoliation led to wines with higher phenolics and volatile compounds concentration. As a consequence, the sensory attribute intensities were influenced too. Selective leaf removal on one side of the canopy (either north or south) allowed us to obtain wines with different chemical and sensory properties. Aglianico wines from early leaf removal on the north side (DN) showed a trend of an increase in the major number of volatile compounds quantified. Leaf removal on both sides (DNS) led to the highest levels of total polyphenols in the wines. Early leaf removal is, therefore, effective in modulating the properties of grapes and wines.

Author Contributions: Conceptualization, G.G. and L.T.; methodology, G.G., L.T. and M.V.; validation, M.V. and V.M.P.; formal analysis, M.V. and V.M.P.; investigation, D.I.; resources, G.G., L.T. and M.V.; writing—original draft preparation, D.I., M.V. and V.M.P.; writing—review and editing, L.T. and G.G.; visualization, M.V. and V.M.P.; supervision, G.G., M.V. and V.M.P.; funding acquisition, G.G. and L.T. All authors have read and agreed to the published version of the manuscript.

Funding: This research received no external funding.

Institutional Review Board Statement: Not Applicable.

Informed Consent Statement: Not Applicable.

Data Availability Statement: Not Applicable.

Acknowledgments: Rías Baixas AOC sensory panel.

Conflicts of Interest: The authors declare no conflict of interest.

\section{References}

1. Intrieri, C.; Filippetti, I.; Allegro, G.; Centinari, M.; Poni, S. Early defoliation (hand vs. mechanical) for improved crop control and grape composition in Sangiovese (Vitis vinifera L.). Aust. J. Grape Wine Res. 2008, 14, 25-32. [CrossRef]

2. Poni, S.; Casalini, L.; Bernizzoni, F.; Civardi, S.; Intrieri, C. Effects of early defoliation on shoot photosynthesis, yield components, and grape composition. Am. J. Enol. Vitic. 2006, 57, 397-407.

3. VanderWeide, J.; Gottschalk, C.; Schultze, S.R.; Nasrollahiazar, E.; Poni, S.; Sabbatini, P. Impacts of Pre-bloom Leaf Removal on Wine Grape Production and Quality Parameters: A Systematic Review and Meta-Analysis. Front. Plant Sci. 2021, $11,621585$. [CrossRef] [PubMed] 
4. Guidoni, S.; Oggero, G.; Cravero, S.; Rabino, M.; Cravero, M.C.; Balsari, P. Manual and mechanical leaf removal in the bunch zone (Vitis vinifera L., cv Barbera): Effects on berry composition, health, yield and wine quality, in a warm temperate area. OENO One 2008, 42, 49-58. [CrossRef]

5. Tardaguila, J.; de Toda, F.M.; Poni, S.; Diago, M.P. Impact of early leaf removal on yield and fruit and wine composition of Vitis vinifera L. Graciano and Carignan. Am. J. Enol. Vitic. 2010, 61, 372-381.

6. Pastore, C.; Zenoni, S.; Fasoli, M.; Pezzotti, M.; Tornielli, G.B.; Filippetti, I. Selective defoliation affects plant growth, fruit transcriptional ripening program and flavonoid metabolism in grapevine. BMC Plant Biol. 2013, 13, 30. [CrossRef]

7. Poni, S.; Bernizzoni, F.; Civardi, S.; Libelli, N. Effects of pre-bloom leaf removal on growth of berry tissues and must composition in two red Vitis vinifera L. cultivars. Aust. J. Grape Wine Res. 2009, 15, 185-193. [CrossRef]

8. Diago, M.P.; Vilanova, M.; Tardaguila, J. Effects of timing of manual and mechanical early defoliation on the aroma of Vitis vinifera L. tempranillo wine. Am. J. Enol. Vitic. 2010, 61, 382-391.

9. Torres, N.; Martínez-Lüscher, J.; Porte, E.; Yu, R.; Kaan Kurtural, S. Impacts of leaf removal and shoot thinning on cumulative daily light intensity and thermal time and their cascading effects of grapevine (Vitis vinifera L.) berry and wine chemistry in warm climates. Food Chem. 2021, 343, 128447. [CrossRef]

10. Pastore, C.; Allegro, G.; Valentini, G.; Muzzi, E.; Filippetti, I. Anthocyanin and flavonol composition response to veraison leaf removal on Cabernet Sauvignon, Nero d'Avola, Raboso Piave and Sangiovese Vitis vinifera L. cultivars. Sci. Hort. 2017, 218, 147-155. [CrossRef]

11. Sivilotti, P.; Herrera, J.C.; Lisjak, K.; Baša Česnik, H.; Sabbatini, P.; Peterlunger, E.; Castellarin, S.D. Impact of Leaf Removal, Applied before and after Flowering, on Anthocyanin, Tannin, and Methoxypyrazine Concentrations in Merlot' (Vitis vinifera L.) Grapes and Wines. J. Agric. Food Chem. 2016, 64, 4487-4496. [CrossRef] [PubMed]

12. Palliotti, A.; Tombesi, S.; Silvestroni, O.; Lanari, V.; Gatti, M.; Poni, S. Changes in vineyard establishment and canopy management urged by earlier climate-related grape ripening: A review. Sci. Hort. 2014, 178, 43-54. [CrossRef]

13. Torres, N.; Martínez-Lüscher, J.; Porte, E.; Kurtural, S.K. Optimal Ranges and Thresholds of Grape Berry Solar Radiation for Flavonoid Biosynthesis in Warm Climates. Front. Plant Sci. 2020, 11, 931. [CrossRef] [PubMed]

14. Van Leeuwen, C.; Darriet, P. The Impact of Climate Change on Viticulture and Wine Quality. J. Wine Econon. 2016, 11, 150-167. [CrossRef]

15. Van Leeuwen, C.; Destrac-Irvine, A.; Dubernet, M.; Duchêne, E.; Gowdy, M.; Marguerit, E.; Pieri, P.; Parker, A.; de Rességuier, L.; Ollat, N. An update on the impact of climate change in viticulture and potential adaptations. Agronomy 2019, 9, 514. [CrossRef]

16. Rapp, A.; Mandery, H. Wine aroma. Experientia 1986, 42, 873-884. [CrossRef]

17. Styger, G.; Prior, B.; Bauer, F.F. Wine flavor and aroma. J. Ind. Microbiol. Biotechnol. 2011, 38, 1145-1159. [CrossRef]

18. Xu, X.-Q.; Cheng, G.; Duan, L.-L.; Jiang, R.; Pan, Q.-H.; Duan, C.-Q.; Wang, J. Effect of training systems on fatty acids and their derived volatiles in Cabernet Sauvignon grapes and wines of the north foot of Mt. Tianshan. Food Chem. 2015, 181, 198-206. [CrossRef]

19. Friedel, M.; Stoll, M.; Patz, C.D.; Will, F.; Dietrich, H. Impact of light exposure on fruit composition of white "Riesling" grape berries (Vitis vinifera L.). Vitis-J. Grapevine Res. 2015, 54, 107-116.

20. Gregan, S.M.; Wargent, J.J.; Liu, L.; Shinkle, J.; Hofmann, R.; Winefield, C.; Trought, M.; Jordan, B. Effects of solar ultraviolet radiation and canopy manipulation on the biochemical composition of Sauvignon Blanc grapes. Aust. J. Grape Wine Res. 2012, 18, 227-238. [CrossRef]

21. Kozina, B.; Karoglan, M.; Herjavec, S.; Jeromel, A.; Orlic, S. Influence of basal leaf removal on the chemical composition of Sauvignon Blanc and Riesling wines. J. Food Agric. Environ. 2008, 6, $28-33$.

22. Šuklje, K.; Antalick, G.; Buica, A.; Langlois, J.; Coetzee, Z.A.; Gouot, J.; Schmidtke, L.M.; Deloire, A. Clonal differences and impact of defoliation on Sauvignon blanc (Vitis vinifera L.) wines: A chemical and sensory investigation. J. Sci. Food Agric. 2016, 96, 915-926. [CrossRef] [PubMed]

23. Feng, H.; Skinkis, P.A.; Qian, M.C. Pinot noir wine volatile and anthocyanin composition under different levels of vine fruit zone leaf removal. Food Chem. 2017, 214, 736-744. [CrossRef] [PubMed]

24. Verzera, A.; Tripodi, G.; Dima, G.; Condurso, C.; Scacco, A.; Cincotta, F.; Giglio, D.M.L.; Santangelo, T.; Sparacio, A. Leaf removal and wine composition of Vitis vinifera L. cv. Nero d'Avola: The volatile aroma constituents. J. Sci. Food Agric. 2016, 96, 150-159. [CrossRef] [PubMed]

25. Baiano, A.; Mentana, A.; Quinto, M.; Centonze, D.; Previtali, M.A.; Varva, G.; Del Nobile, M.A.; De Palma, L. Volatile composition and sensory profile of wines obtained from partially defoliated vines: The case of Nero di Troia wine. Eur. Food Res. Technol. 2017, 243, 247-261. [CrossRef]

26. Vilanova, M.; Diago, M.P.; Genisheva, Z.; Oliveira, J.M.; Tardaguila, J. Early leaf removal impact on volatile composition of Tempranillo wines. J. Sci. Food Agric. 2012, 92, 935-942. [CrossRef]

27. Francis, I.L.; Newton, J.L. Determining wine aroma from compositional data. Aust. J. Grape Wine Res. 2005, 11, 114-126. [CrossRef]

28. Meilgaard, M.; Vance Civille, G.; Thomas Carr, B. Sensory Evaluation Techniques, 3rd ed.; CRC Press: Boca Raton, FL, USA, 1999.

29. Stone, H.; Sidel, J.L. Quantitative descriptive analysis: Developments, applications and the future. Food Technol. J. 1998, 52, 48-52.

30. Vilanova, M.; Campo, E.; Escudero, A.; Graña, M.; Masa, A.; Cacho, J. Volatile composition and sensory properties of Vitis vinifera red cultivars from North West Spain: Correlation between sensory and instrumental analysis. Anal. Chim. Acta 2012, 720, 104-111. [CrossRef] 
31. Vilanova, M.; Genisheva, Z.; Masa, A.; Oliveira, J.M. Correlation between volatile composition and sensory properties in Spanish Albariño wines. Microchem. J. 2010, 95, 240-246. [CrossRef]

32. Vilanova, M.; Rodríguez-Nogales, J.M.; Vila-Crespo, J.; Yuste, J. Influence of water regime on yield components, must composition and wine volatile compounds of Vitis vinifera cv. Verdejo. Aust. J. Grape Wine Res. 2019, 25, 83-91. [CrossRef]

33. Verdenal, T.; Zufferey, V.; Dienes-Nagy, A.; Bourdin, G.; Gindro, K.; Viret, O.; Spring, J.L. Timing and intensity of grapevine defoliation: An extensive overview on five cultivars in Switzerland. Am. J. Enol. Vitic. 2019, 70, 427-434. [CrossRef]

34. Suriano, S.; Alba, V.; Tarricone, L.; Di Gennaro, D. Maceration with stems contact fermentation: Effect on proanthocyanidins compounds and color in Primitivo red wines. Food Chem. 2015, 15, 382-389. [CrossRef] [PubMed]

35. De Lorenzis, G.; Rustioni, L.; Parisi, S.G.; Zoli, F.; Brancadoro, L. Anthocyanin biosynthesis during berry development in corvina grape. Sci. Hortic. 2016, 212, 74-80. [CrossRef]

36. Czemmel, S.; Heppel, S.C.; Bogs, J. R2R3 MYB transcription factors: Key regulators of the flavonoid biosynthetic pathway in grapevine. Protoplasma 2012, 249, 109-118. [CrossRef] [PubMed]

37. Tarricone, L.; Faccia, M.; Masi, G.; Gambacorta, G. The Impact of Early Basal Leaf Removal at Different Sides of the Canopy on Aglianico Grape Quality. Agriculture 2020, 10, 630. [CrossRef]

38. Sternad Lemut, M.; Trost, K.; Sivilotti, P.; Arapitsas, P.; Vrhovsek, U. Early versus late leaf removal strategies for Pinot Noir (Vitis vinifera L.): Effect on colour-related phenolics in young wines following alcoholic fermentation. J. Sci. Food Agric. 2013, 93, 3670-3681. [CrossRef]

39. Kemp, B.S.; Harrison, R.; Creasy, G.L. Effect of mechanical leaf removal and its timing on flavan-3-ol composition and concentrations in Vitis vinifera L. cv. Pinot Noir wine. Aust. J. Grape Wine Res. 2011, 17, 270-279. [CrossRef]

40. Verdenal, T.; Zufferey, V.; Dienes-Nagy, A.; Gindro, K.; Belcher, S.; Lorenzini, F.; Rösti, J.; Koestel, C.; Spring, J.L.; Viret, O. Pre-flowering defoliation affects berry structure and enhances wine sensory parameters. OENO One 2017, 51, 263-275. [CrossRef]

41. Mucalo, A.; Budić-Leto, I.; Lukšić, K.; Maletić, E.; Zdunić, G. Early Defoliation Techniques Enhance Yield Components, Grape and Wine Composition of cv. Trnjak (Vitis vinifera L.) in Dalmatian Hinterland Wine Region. Plants 2021, 10, 551. [CrossRef]

42. Moreno, D.; Valdés, E.; Urierte, D.; Gamero, E.; Talaverano, I.; Vilanova, M. Early leaf removal applied in warm climatic conditions: Impact on Tempranillo wine volatiles. Food Res. Int. 2017, 98, 50-58. [CrossRef] [PubMed]

43. Reynolds, A.G.; Wardle, D.A. Influence of fruit microclimate on monoterpene levels of Gewurztraminer. Am. J. Enol. Vitic. 1989, 40, 149-154.

44. Bubola, M.; Persurie, D.; Ganie, K.K.; Cossetto, M. Influence of timing and intensity of basal leaf removal on aromatic composition of cv. Istrian Malvasia wines. In Abstracts Book III Int. Symp; Malvasias: Canary Islands, Spain, 2009; pp. 64-65.

45. Kliewer, W.M.; Smart, R.E. Canopy manipulation for optimizing vine microclimate, crop yield and composition of grapes. In Manipulation of Fruiting; Wright, C.J., Ed.; Butterworth \& Co.: Nottingham, UK, 1989; pp. 275-291.

46. Hunter, J.J.; Visser, J.H. The effect of partial defoliation, leaf position and developmental stage of the vine on the photosynthetic activity of Vitis vinifera L. cv. Cabernet Sauvignon. S. Afr. J. Enol. Vitic. 1988, 9, 9-15. [CrossRef]

47. Price, S.; Breen, P.; Valladao, M.; Watson, B. Cluster sun exposure and quercetin in Pinot noir grapes and wine. Am. J. Enol. Vitic. 1995, 46, 187-194.

48. Giovanelli, G.; Brenna, O. Evolution of some phenolics components, carotenoids and chorophylls during ripening of three Italian grape varieties. Eur. Food Res. Technol. 2007, 225, 145-150. [CrossRef]

49. Percival, D.C.; Fisher, K.H.; Sullivan, J.A. Use of fruit zone leaf removal with Vitis vinifera L. cv. Riesling grapevines. II. Effect on fruit composition, yield, and occurrence of bunch rot. Am J Enol Vitic. 1994, 45, 133-139.

50. Smart, R.E.; Dick, J.K.; Gravett, I.M.; Fisher, B.M. Canopy management to improve grape and yield and wine quality-principles and practices. S. Afr. J. Enol Vitic. 1990, 11, 3-17. [CrossRef]

51. Downey, M.O.; Dokoozlian, N.K.; Krstic, M.P. Cultural practice and environmental impacts on the flavonoid composition of grapes and wine: A review of recent research. Am. J. Enol. Vitic. 2006, 57, 257-268.

52. Palliotti, A.; Gardi, T.; Berrios, J.G.; Civardi, S.; Poni, S. Early source limitation as a tool for yield control and wine quality improvement in a high-yielding red Vitis vinifera L. cultivar. Sci. Hortic. 2012, 145, 10-16. [CrossRef]

53. Atanasova, B.; Danguin, T.T.; Langlois, D.; Nicklaus, S.; Chabanet, C.; Etiévant, P. Perception of wine fruity and woody notes: Influence of peri-threshold odorants. Food Qual. Pref. 2005, 16, 504-510. [CrossRef]

54. Gambacorta, G.; Trani, A.; Fasciano, C.; Paradiso, V.M.; Faccia, M. Effects of prefermentative cold soak on polyphenols and volatiles of Aglianico, Primitivo and Nero di Troia red wines. Food Sci. Nutr. 2019, 7, 483-491. [CrossRef] [PubMed]

55. Di Stefano, R.; Cravero, M.C. Methods for grape phenolic compounds study. Riv. Vitic. Enol. 1991, 44, $37-45$.

56. Glories, Y. La couleur des vins rouges. 2e partie: Mesure, origine et interprétation. OENO One 1984, 18, 253-271. [CrossRef]

57. Trani, A.; Verrastro, V.; Punzi, R.; Faccia, M.; Gambacorta, G. Phenols, Volatiles and Sensory Properties of Primitivo Wines from the "Gioia Del Colle" PDO Area. S. Afr. J. Enol. Vitic. 2016, 37, 139-148. [CrossRef]

58. Guerrero, R.F.; Liazid, A.; Palma, M.; Puertas, B.; González-Barrio, R.; Gil-Izquierdo, Á.; García-Barroso, C.; Cantos-Villar, E. Phenolic characterisation of red grapes autochthonous to Andalusia. Food Chem. 2009, 112, 949-955. [CrossRef]

59. Rusjan, D.; Veberič, R.; Mikulič-Petkovšek, M. The response of phenolic compounds in grapes of the variety 'Chardonnay'(Vitis vinifera L.) to the infection by phytoplasma Bois noir. Eur. J. Plant Pathol. 2012, 133, 965-974. [CrossRef]

60. Bai, B.; He, F.; Yang, L.; Chen, F.; Reeves, M.J.; Li, J. Comparative study of phenolic compounds in Cabernet Sauvignon wines made in traditional and Ganimede fermenters. Food chem. 2013, 141, 3984-3992. [CrossRef] 
61. Pati, S.; Crupi, P.; Benucci, I.; Antonacci, D.; Di Luccia, A.; Esti, M. HPLC-DAD-MS/MS characterization of phenolic compounds in white wine stored without added sulfite. Food Res. Int. 2014, 66, 207-215. [CrossRef]

62. Coelho, E.; Lemos, M.; Genisheva, Z.; Domingues, L.; Vilanova, M.; Oliveira, J.M. Simple and quick LLME/GC-MS methodology to quantify minor volatile compounds in alcoholic beverages. Molecules 2020, 25, 621. [CrossRef]

63. Lawless, H.T.; Heymann, H. Descriptive Analysis. Sensory Evaluation of Food. Principles and Practices; Chapman \& Hall: New York, NY, USA, 1998.

64. Dravnieks, A.; Bock, F.C. Comparison of odours directly and through profiling (ITT Research Institute, Chicago, IL 60610). Chem. Sense. Flav. 1978, 3, 36-54. [CrossRef] 